\title{
Temperatura do Ar, Densidade de Volume Construído e Topografia em Belo Horizonte/MG
}

\section{Air Temperature, Building Volume Density and Topography in Belo Horizonte/MG}

\author{
Daniele Gomes Ferreira ${ }^{1} \bowtie\left(i D\right.$, Carlos Fernando Ferreira Lobo ${ }^{\circledR} \varangle$, Wellington Lopes Assis ${ }^{3} \bowtie$ \\ 1 Universidade Federal de Minas Gerais, dani.gferreira@yahoo.com.br \\ http://orcid.org/0000-0001-9890-1963 \\ 2 Universidade Federal de Minas Gerais, carlosfflobo@gmail.com \\ 3 Universidade Federal de Minas Gerais, assisw@gmail.com \\ Recebido (Received): 23/03/2018 \\ Aceito (Accepted): 11/07/2018
}

\begin{abstract}
Resumo: A temperatura do ar tem variação espacial em áreas urbanas decorrente de diversos fatores, dentre esses destacam-se o uso e ocupação do solo e a topografia. Este artigo apresenta uma aplicação do método de regressão geograficamente ponderada (geographically weighted regression - GWR) para avaliar a relação entre essas variáveis para o caso do município de Belo Horizonte (MG) em recorte temporal correspondente ao mês de agosto, caracterizado por período seco e com condição de céu claro. A densidade de volume construído das edificações e a altitude foram definidas como variáveis explicativas e a temperatura média do ar a variável dependente. Os resultados obtidos apontaram uma baixa predição dos métodos espaciais na explicação da relação entre as variáveis. Observou-se que a melhor correlação ocorreu nas análises da GWR para altitude e temperatura, fato que aponta para um predomínio da atuação de fatores geoecológicos naturais na configuração climática do município. Mesmo com ressalvas e limitações inerentes ao método estatístico, que teoricamente apresenta um tipo de regressão linear, verifica-se que essa técnica, associada a plataformas de sistema de informação geográfica, auxilia na interpretação dos resultados em uma escala local, o que pode melhorar a compreensão da contribuição dos diversos fatores no balanço de energia em ambiente urbano. Ao mesmo tempo, o uso do geoprocessamento permite a atualização constante da informação, sendo que novos dados podem ser agregados aos modelos, otimizando sua capacidade analítica, em uma linguagem acessível a tomadores de decisão nas cidades.
\end{abstract}

Palavras-chave: Cobertura do Solo; Relevo; Clima Urbano; Regressão Geograficamente Ponderada.

\begin{abstract}
The air temperature presents spatial variation in urban areas due to several factors, among which stand out the land use, the land cover and the topography. This article shows the use of geographically weighted regression method (GWR) to analyse the relationship between these variables for the case of the city of Belo Horizonte $(M G)$ in a dry period and clear sky condition which characterized the month of August. The building volume density and the altitude were defined as explanatory variables and the mean air temperature was the dependent variable. The results indicated a low prediction of the spatial methods in the explanation of the relation between the variables. The best correlation in the GWR analysis occurred for altitude and temperature, which points out a predominance of geoecological factors in the climatic condition of the city. Even with the limitations inherent to the statistical method, that theoretically presents a linear regression type, it is verified that this technique, associated with geographic information system platforms, contributed to the interpretation of the results in a local scale, and it can improve the understanding of the influence of the various parameters in the energy balance in the urban environment. At the same time, geoprocessing allows information update, and new data can be added to the models to improve their analytical capacity in an accessible language to decision makers in cities.
\end{abstract}

Keywords: Land Cover; Relief; Urban Climate; Geographically Weighted Regression. 


\section{Introdução}

A concentração da população mundial em áreas urbanas é crescente e atualmente mais da metade desta vive em cidades (UNITED NATIONS, 2015). No Brasil, mais de 80\% da população é urbana (IBGE, 2010), metade desta população está concentrada nos 25 maiores aglomerados urbanos distribuídos no país (IPEA, 2016) e grande parte do território nacional encontra-se em clima tropical. Uma consequência dessa concentração populacional é a urbanização do território, o que causa alteração da cobertura e do uso do solo e, consequentemente, provoca modificações no clima local. Os principais problemas relacionados ao clima em grandes aglomerações urbanas situadas em clima tropical referem-se a baixa dispersão de poluentes atmosféricos, decorrente geralmente da baixa velocidade do vento nestas regiões, altos níveis de estresse térmico e a necessidade de resfriamento do espaço urbano diante das altas temperaturas (ROTH, 2007).

Apesar dessas constatações e do aumento de estudos na área do clima urbano, ainda há lacunas conceituais e de conhecimento na integração dos processos de desenvolvimento urbano em modelos de estudo em escalas regional e global (OKE et al., 2017). Especificamente em países em desenvolvimento localizados em clima tropical, os quais tiveram o maior crescimento da população urbana nas décadas passadas (ROTH, 2007), a escassez de informações climáticas é ainda maior (ROTH, 2007; OKE et al., 2017), o que demonstra a necessidade de investimento em pesquisa nestas regiões , em especial no diz respeito ao impacto das diferentes morfologias urbanas e sua relação com o clima (ROTH, 2007).

Os estudos do clima urbano no Brasil inicialmente tiveram uma maior contribuição de geógrafos (décadas de 1970 e 1980) e, posteriormente, a contribuição de arquitetos e engenheiros nessa temática mostrou-se mais expressiva (ASSIS, 2006), mas ainda são realizados em pequeno número quando comparados às pesquisas empreendidas em países desenvolvidos. Abordagens multi e transdisciplinares se mostram relevantes e fundamentais para avançar em direção a uma ciência que possa ser mais abrangente, sendo importante a integração de múltiplas disciplinas para a compreensão da cidade e sua relação com o clima. Uma dessas possíveis interações disciplinares é entre a geografia e o urbanismo com a apropriação de ferramentas de sistemas de informações geográficas (SIG), amplamente utilizadas pelas duas disciplinas e de técnicas de estatística espacial, mais difundida em aplicações da geografia. Essa integração de ferramentas permite aprimorar a representação e a análise de características da cidade associadas a variáveis climáticas por meio de plataformas que são facilmente apreendidas por planejadores urbanos. Desta forma, pode-se avançar em um dos desafios da climatologia urbana que é de traduzir o conhecimento científico em ferramentas aplicáveis ao planejamento de cidades (OKE et al., 2017).

O objetivo deste artigo foi realizar a integração de duas variáveis descritivas, representativas do contexto urbano e da geografia física, sendo uma delas as edificações e a outra a topografia, para verificar uma possível relação com a variação da temperatura do ar. Esta análise foi feita para a cidade de Belo Horizonte, localizada em clima tropical e onde a topografia tem grande variação ao longo do território. Uma questão que se apresentou foi em relação à representação da variável climática para uma extensão territorial a partir de medições pontuais de campo. As técnicas empregadas para a coleta dos dados de temperatura, os limites da representação e da escala adotada, apropriados de abordagens feitas pela geografia, são discutidos no trabalho.

A avaliação da influência dos elementos construídos e do relevo na variação do comportamento de um parâmetro climático, utilizando instrumento de representação espacial de fácil apreensão por diversos tomadores de decisão, mostra-se uma contribuição para a produção e a transmissão do conhecimento em clima urbano. A integração de métodos apropriados por diferentes disciplinas, justifica-se como um objetivo mais amplo de abordar de forma transdisciplinar esta temática, incorporando elementos naturais e humanos na análise do clima.

\subsection{As Edificações e o Campo Térmico Urbano: Controvérsias e Evidências}

As áreas urbanizadas alteram a dinâmica das variáveis climáticas em escala local, fenômeno que pode ser definido como clima urbano (LANDSBERG, 1981; ARNFIELD, 2003). Tal fato ocorre devido à modificação que as superfícies, os materiais e as atividades nas áreas urbanas provocam nos balanços de energia, massa e movimento na camada limite planetária - esta camada estende-se da superfície do solo até, no máximo, dois a três quilômetros de altura (VIANELLO; ALVES, 1991), caracterizada por movimentos turbulentos gerados pelo atrito do ar junto à superfície e pelo intenso aquecimento basal, processos que facilitam a troca de vapor d'água e calor entre o solo e a atmosfera. (VAREJÃO-SILVA, 2000).

O clima urbano também pode ser entendido como um sistema de organização complexa, composto por subsistemas (termodinâmico, físico-químico e hidrometeórico) e seus respectivos canais de percepção 
(conforto térmico, qualidade do ar e impacto meteórico) (MONTEIRO, 2003). De acordo com este autor, os elementos componentes deste sistema têm conexões intrínsecas, que não são definidas somente pela superposição ou adição de fenômenos isolados, mas também pela interrelação com as partes que o constituem.

No ambiente urbano, o balanço de energia é determinado, de modo geral, por fatores de ganho, perda e armazenamento de energia na camada atmosférica acima da superfície urbana (OKE, 1978). Elementos como relevo, morfologia urbana, tipos de superfícies, proporção de espaços abertos, dentre outros, alteram o balanço de energia nas cidades. Alguns elementos climáticos, como a luz solar, apresentam pouca variação em relação ao território da cidade. Outros, como a temperatura do ar e os padrões de vento, por sua vez, apresentam variação têmporo-espacial significativa, pois são influenciados por fatores como a capacidade das edificações de acumular calor, o tipo de cobertura do solo, a orientação das vertentes e a presença de corpos d'água. Especificamente quanto ao relevo, este tem efeito atenuador sobre a temperatura do ar com o aumento da altitude e pode-se considerar uma taxa média de $0,6^{\circ} \mathrm{C}$ de diminuição de temperatura a cada variação de 100 metros da altitude (AYOADE, 1996). As especificidades do clima urbano, portanto, estão relacionadas a padrões espaciais que são heterogêneos na extensão de uma cidade. Assim, para alguns tipos de variáveis climáticas a relação espacial é determinante na avaliação dos fenômenos físicos.

De acordo com Oke (1978), as áreas urbanas geralmente são mais quentes que seu entorno não urbanizado em períodos noturnos. A forma de implantação das edificações em áreas verticalizadas, conformando cânions urbanos, altera os regimes de balanço de energia e radiação das superfícies, apresentando uma grande complexidade espacial e temporal. A geometria das edificações e dos cânions urbanos pode, por exemplo, aumentar a área de superfície exposta a processos de troca de energia; controlar e tornar mais complexa a distribuição espacial da radiação solar direta e influenciar a perda de radiação de onda longa para o céu (OKE, 1982), mas ao mesmo tempo pode impedir a incidência direta de radiação solar nas faces das edificações por auto sombreamento, no caso de conjuntos de edifícios altos. A obstrução da visão do céu pelas edificações tem como uma de suas consequências a diminuição da velocidade do resfriamento superficial durante as noites de céu claro e calmaria, condições ideais para a formação da ilha de calor noturna (OKE, 1978). Assim, a geometria e o tipo de material empregado nas edificações caracterizam-se como importantes parâmetros de análise do clima nas cidades.

Algumas formas de representação da geometria urbana seriam por meio da determinação do fator de visão de céu, pelo volume da edificação e por parâmetros urbanísticos. Estudos apontam a relação da geometria urbana com variáveis climáticas, sendo que alguns exemplos são apresentados a seguir, especificamente relacionados ao campo térmico urbano. Tso et al. (1990) demonstraram que, ao incluir o termo de armazenamento de calor associado à massa construída das edificações em modelo de balanço de energia, houve melhora na previsão da variação diurna de temperatura para a determinação do balanço de energia realizada para a cidade de Kuala Lumpur (Malásia). Estes mesmos autores concluíram que a massa construída teve influência sobre o atraso da temperatura máxima do ar.

Vilela et al. (2009) analisaram variáveis climáticas (temperatura do ar e umidade relativa) e variáveis urbanas (massa construída e fator de visão de céu) em um recorte urbano em Belo Horizonte a partir de dados coletados em campo. Aplicando método de regressão linear observou-se que a massa construída apresentou menor correlação com a temperatura do que o fator de visão de céu. A umidade, por sua vez, pareceu ter baixa correlação com a massa construída. Neste estudo as correlações encontradas entre as variáveis foram baixas. É importante ressaltar que este trabalho foi realizado para uma área específica ao sul da cidade de Belo Horizonte, onde a topografia atinge as maiores altitudes e as edificações não são representativas da diversidade de tipologias existentes na cidade. Assim, os resultados encontrados foram pontuais e não poderiam ser extrapolados para outras áreas da cidade.

Morais (2011) e Gusson e Duarte (2016) compararam dois recortes urbanos com diferentes densidades de construção nas cidades de Salvador e São Paulo, respectivamente. No caso da cidade de Salvador, as áreas foram representadas por: 1) ocupação espontânea, com edificações predominantemente baixas, atingindo até quatro pavimentos e alta densidade de ocupação (Nordeste de Amaralina) e 2) ocupação planejada, com edifícios verticalizados e média densidade de ocupação (Pituba). Em São Paulo, a densidade populacional das duas áreas analisadas era semelhante, enquanto que a densidade construída se diferenciava, sendo uma delas com predomínio de edificações horizontais (Brasilândia) e outra verticalizada (Bela Vista). Em ambas as cidades a densidade construída foi determinada por parâmetros urbanísticos como coeficiente de aproveitamento (razão entre a área total construída e a área do terreno), taxa de ocupação (razão entre a área projetada da edificação e a área do terreno), dentre outros. Constatou-se que as áreas mais densamente ocupadas tanto em Salvador como em São Paulo, apesar de não verticalizadas, apresentaram maiores 
amplitudes de temperatura do ar. No caso de Salvador, a área mais densamente ocupada (Nordeste de Amaralina) também apresentou os maiores valores de temperatura do ar medidos durante o dia.

Ivanjnsic et al. (2014) avaliaram a intensidade e a morfologia da ilha de calor em cidade de pequeno porte (Ljutomer, Eslovênia), testando a utilidade de método de regressão geograficamente ponderada (GWR geographically weighted regression) na análise da relação entre temperatura média do ar e fatores urbanos que teriam influência nesta variável. Com base em dados medidos de temperatura, a análise de regressão confirmou a importância de variáveis explicativas locais (distância da área urbana, relação com a topografia e diversidade de cobertura do solo) e globais (volume construído e direção da declividade do relevo) na explicação da variação da temperatura média do ar. O volume construído teve uma influência positiva na temperatura média do ar, concluindo que se o volume construído sobe para $1.000 \mathrm{~m}^{3}$, a temperatura média do ar aumenta em $0,06^{\circ} \mathrm{C}$ neste estudo de caso.

Em estudo para a cidade de Hong Kong utilizando metodologia de mapas climáticos (NG, 2015), a densidade urbana foi representada por meio do volume construído das edificações. Neste tipo de análise climática não há uma avaliação estatística da influência deste parâmetro urbano na variação de ganho de carga térmica. Esta relação é determinada de forma empírica, a partir do conhecimento dos climatologistas, os quais apontam qualitativamente qual a influência entre as diversas variáveis avaliadas. Para Hong Kong, considerou-se que quanto maior o volume construído, maior seria o ganho de carga térmica. Outros trabalhos em que se aplica esta mesma metodologia, revistos por Ren et al. (2011), também atribuem uma relação positiva entre a carga térmica e o volume construído, sendo que quanto maior o volume maior seria o ganho de carga térmica no ambiente urbano. Neste caso não é possível fazer uma associação direta entre este ganho e aumento de temperatura, pois a alteração do parâmetro climático depende de outros fatores.

Dos estudos citados, a massa construída e o volume edificado seriam variáveis equivalentes quanto à representação das edificações - ambos correspondem ao volume do edifício. Em alguns trabalhos, a avaliação da relação deste parâmetro urbano com a temperatura foi feita utilizando métodos estatísticos tradicionais (VILELA et al., 2009) ou estatística espacial (IVANJNSIC et al., 2014). Em outros (MORAIS, 2011; GUSSON; DUARTE, 2016; NG, 2015; REN et al., 2011), apesar de se considerar a variável urbana na análise do clima, não foram feitas correlações para estimativa de sua influência na variação da temperatura ou na determinação do ganho de carga térmica no balanço de energia urbano. Contudo, estes estudos apontam diferenças quanto a relação entre a temperatura e os elementos edificados. Enquanto os dois primeiros observaram uma variação maior de temperatura do ar em áreas mais densamente ocupadas e não naquelas com maior verticalização, os outros dois últimos, de forma empírica, estabeleceram uma relação de aumento de carga térmica associada ao volume construído e não à densidade de ocupação. Tal fato demonstra que a relação entre estas variáveis não é um consenso e precisa de maior investigação. Ivanjnsic et al. (2014), por sua vez, utiliza o método de estatística espacial para uma cidade de pequeno porte, apontando uma metodologia para estudo da relação entre variáveis naturais e urbanas. Considerando que o clima urbano é um sistema complexo e que o estudo de suas partes isoladas e somadas não representam a sua totalidade (MONTEIRO, 2003), mostra-se necessário avançar na investigação da relação de outras variáveis (urbanas e naturais) e sua interação com os parâmetros climáticos.

Neste sentido, a estatística espacial e o geoprocessamento têm permitido o aprimoramento e o refinamento de um conjunto de instrumentos voltados ao mapeamento, análise e representação de dados climáticos, inclusive para o planejamento urbano, e que dispõem de ferramentas em que é possível testar relações entre as diversas variáveis que compõem o clima urbano. As plataformas SIG mostram-se um instrumento viável para a espacialização, o monitoramento, a avaliação e a quantificação dos topoclimas e mesoclimas e suas relações com as diferentes formas de ocupação e organização do tecido urbano. Tais informações, sejam quantitativas ou qualitativas, alfanuméricas ou espaciais, necessitam de constantes atualizações. Neste contexto, o uso de técnicas e a aplicação de metodologias em SIG tornam-se bastante oportunos face à intenção de atualização permanente das informações obtidas nos experimentos de campo.

Considerando a influência das edificações no balanço de energia urbano e a sua dependência espacial, este artigo tem como objetivo, por meio de estatística espacial, aplicar o método de regressão geograficamente ponderada para avaliar a relação do volume construído e da topografia com a temperatura do ar para toda a extensão da cidade de Belo Horizonte, visto que a relação destas variáveis não é um consenso na literatura e a estatística espacial pode contribuir neste tipo de estudo.

\section{Materiais e Métodos}

A avaliação da relação entre uma variável climática (temperatura do ar), um parâmetro que representa a forma urbana (densidade de volume construído) e o relevo (altitude média) foi feita considerando que a 
forma urbana pode alterar esta variável climática (OKE, 1978) assim como diferenças de altitude e de relevo também afetam este parâmetro em regiões tropicais (BARRY e CHORLEY, 2010). O estudo de caso foi aplicado para a cidade de Belo Horizonte, localizada na região central do Estado de Minas Gerais (Figura 1). O município está entre as dez cidades com maior população do Brasil, com número de habitantes superior a 2,4 milhões e densidade demográfica de cerca de 7.000 habitantes $/ \mathrm{km}^{2}$ (valores referentes ao ano de 2010, conforme dados do Censo Demográfico do IBGE). Compreende uma área de $331 \mathrm{~km}^{2}$ e todo o seu território, dividido em nove Regionais Administrativas, é considerado como zona urbana. O clima do município pode ser classificado como tropical de altitude (ASSIS, 2010), com temperatura média anual de $21^{\circ} \mathrm{C}$ e vento predominante leste com velocidade média anual de $1,4 \mathrm{~m} / \mathrm{s}$.

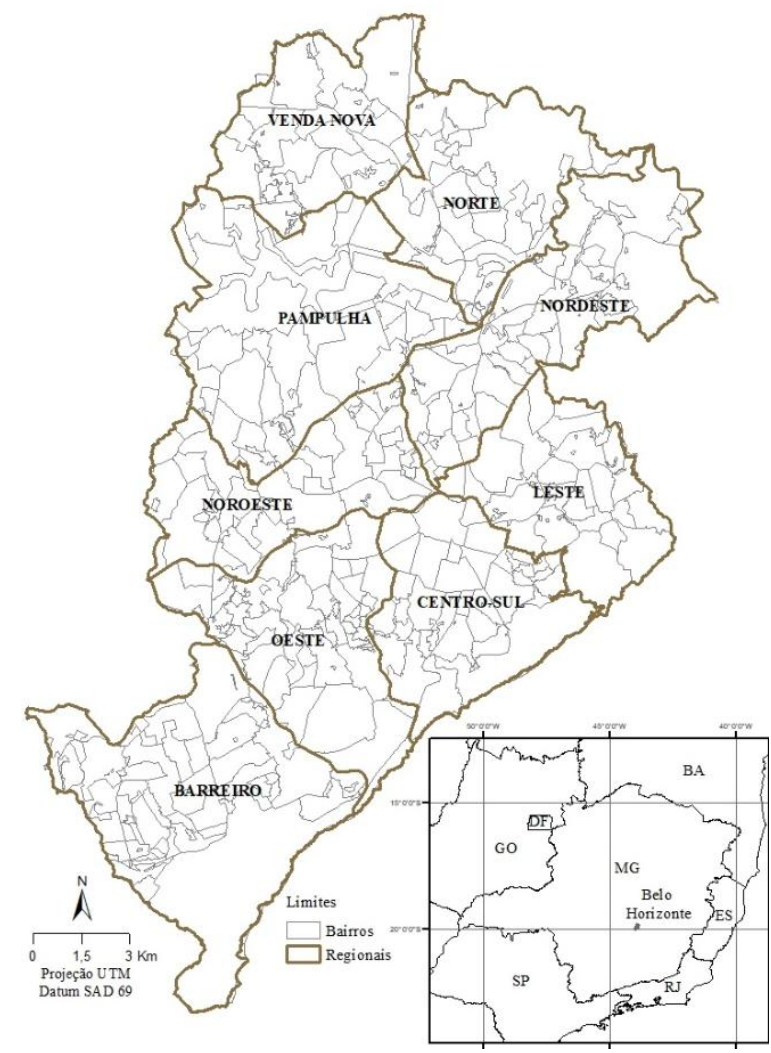

Fonte: Base cartográfica da Prefeitura de Belo Horizonte, elaboração pelos autores, nov. 2017.

Figura 1: Localização, divisão regional e bairros do município de Belo Horizonte/MG

A metodologia do trabalho foi dividida em duas etapas. Na primeira, avaliou-se a relação entre temperatura do ar e volume construído, derivado a partir da área em planta e da altura das edificações. Em seguida foi feita a análise entre os mesmos dados de temperatura e a topografia da cidade. A unidade territorial de análise foi o bairro. Esta é uma unidade espacial amplamente utilizada em estudos geográficos e pela gestão urbana municipal e que se ajusta inclusive à delimitação dos setores censitários utilizada pelo IBGE. Contudo sabe-se que há limitações quanto a representação de dados climáticos nessa escala, já que estes dados não estão associados a divisões administrativas e sim às variações naturais e construídas do território. Por ser uma unidade reconhecida pelo planejamento e gestão urbana, bem como pela população envolvida, optou-se por utilizar esse recorte espacial. Os mapas e dados coletados foram tratados e analisados na plataforma ArcMap/ArcGis ${ }^{\circledR}$.

Os dados de temperatura do ar foram extraídos de Assis (2010), os quais foram obtidos por sensores do tipo termo-higrômetros instalados em abrigos meteorológicos posicionados a $1,5 \mathrm{~m}$ da superfície. Os termohigrômetros foram aferidos conforme os critérios estabelecidos pela Organização Mundial de Meteorologia. A coleta de dados foi realizada em 26 pontos amostrais distribuídos pela cidade, sendo seis estações meteorológicas e 20 abrigos de campo, registrados em intervalos horários entre os dias 21 e 30/08/2008, caracterizado por ser um período seco, cujas condições meteorológicas eram estáveis, com pouca nebulosidade e ventos fracos (Figura 2). A escolha deste período se justifica pois nestas condições climáticas os fenômenos de micro e meso escala e os efeitos das propriedades das superfícies são mais expressivos (OKE, 1978). A temperatura do ar, por sua vez, foi expressa pela média dos registros obtidos no intervalo de tempo por ser uma medida usualmente utilizada para fins meteorológicos (WMO, 2012). A partir da média da temperatura de cada ponto para o período de coleta, utilizou-se o método Função Radial Básica (RBF) para interpolar os dados para todo o município, obtendo-se uma matriz com resolução de 
100x100 metros. Esse raster foi convertido em pontos e posteriormente foram utilizadas as ferramentas Dissolve e Intersect para atribuir um dado de temperatura média para cada bairro da cidade.

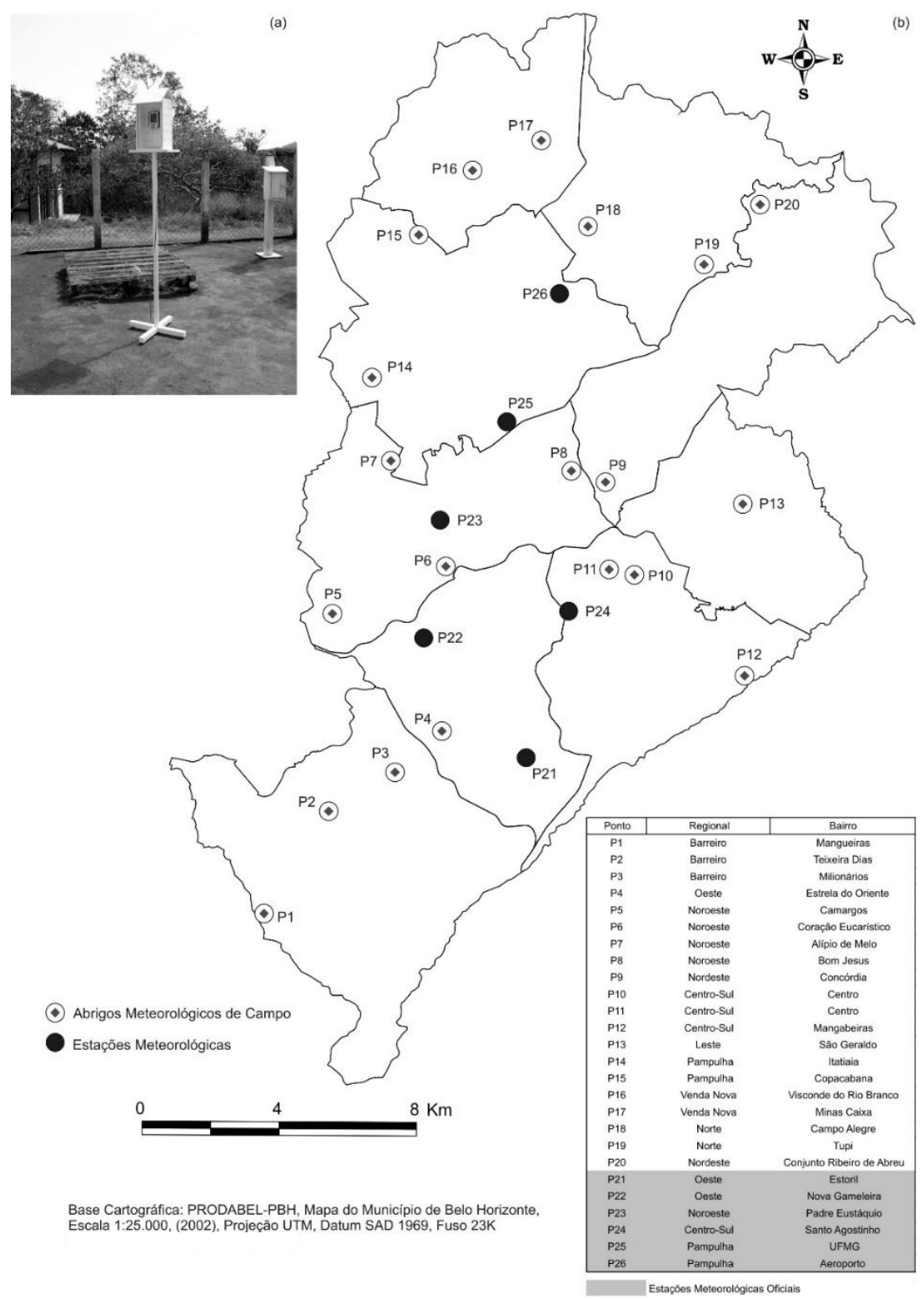

Figura 2: Localização das estações e abrigos meteorológicos no município de Belo Horizonte/MG.

Para o cálculo do volume construído utilizou-se a base de dados cartográficos em formato vetorial fornecida pela Prefeitura de Belo Horizonte, a qual foi construída a partir de levantamento a laser (aerolevantamento) do ano de 2007. A base contém os polígonos das edificações com informações associadas da área dos polígonos e a altura estimada de cada prédio, calculadas pela Prefeitura. Com estes dados foi possível estimar o volume construído multiplicando-se a área em planta pela altura. Posteriormente o mapa vetorial foi convertido em pontos, considerando o centroide de cada polígono. As ferramentas Dissolve e Intersect foram novamente usadas para atribuir um valor de volume construído para cada bairro. Contudo, nessa etapa, a operação foi de soma de valores de volume por bairro. Fez-se uma razão entre o volume construído total por bairro e a área de cada bairro para se obter a densidade de volume construído desta unidade administrativa. Optou-se por adotar a nomenclatura "densidade de volume construído" para a variável que representa a forma urbana em analogia a qualquer medida de densidade, que se expressa pela razão entre uma quantidade de uma grandeza e uma medida de comprimento, superfície ou volume. O termo "densidade construída" utilizado em outros trabalhos aqui citados nem sempre expressam a densidade em termos tridimensionais, como o que se buscou com o cálculo do volume. O mapa de densidade de volume construído foi representado por cinco classes, distribuídas conforme classificação por quebras naturais (Natural Breaks).

O mapa hipsométrico foi gerado a partir de curvas de nível em intervalos de cinco metros fornecido pela Prodabel (2001). Este foi convertido em raster, com grid de 100x100 metros e depois em pontos. A cada 
bairro foi atribuído o valor médio de altitude do conjunto de pontos associados. Assim como no mapa de densidade de volume construído, a altitude também foi representada por cinco classes.

A partir das classes estabelecidas para densidade de volume construído e altitude, foi feita uma análise comparativa inicial com os dados de temperatura do ar utilizando box plot. Realizou-se também uma regressão linear com todo o conjunto de dados, tendo como variável dependente a temperatura do ar. Por meio da estatística espacial, a relação entre as variáveis foi avaliada com base no método GWR. Este método é estimado por uma equação de regressão para cada ponto geográfico com a atribuição de pesos para as observações vizinhas. "Pesos relativamente grandes são atribuídos a pontos próximos da localização e pesos menores são atribuídos a observações distantes do local" (ROGERSON, 2012, p. 285). Para a análise de regressão, admitiu-se a temperatura como variável dependente e a densidade de volume construído e a altitude as variáveis explicativas. Foi estimado, então, o índice de regressão local ( $\mathrm{R}^{2}$ local), para cada polígono e identificados os padrões de distribuição espacial dos resíduos (Std. Resid).

\section{Resultados e Discussões}

A Figura 3 representa a distribuição espacial dos dados de temperatura média do ar, densidade de volume construído e altitude média por bairros no município de Belo Horizonte. Quanto à temperatura (Figura 3a), nota-se que os valores mais baixos estão concentrados na porção sul e sudeste do município, especialmente nas partes mais elevadas do terreno na face oeste da Serra do Curral (Figura 3c). A diferença de altitude de $500 \mathrm{~m}$ entre a região mais baixa da cidade, a norte, e o ponto mais alto naturalmente já poderia indicar uma diferença de temperatura de cerca de $3^{\circ} \mathrm{C}$, considerando a redução de temperatura de $0,6^{\circ} \mathrm{C}$ a cada $100 \mathrm{~m}$ de variação da altitude (AYOADE, 1996). Esta diferença praticamente se confirma a partir da amplitude térmica observada, que foi de $2,5^{\circ} \mathrm{C}$. Há, dessa forma, uma clara associação entre os valores de temperatura e altitude média por bairro, o que corrobora os efeitos do relevo como atenuador da temperatura (BARRY; CHORLEY, 2010). Contudo, a relação entre essas duas variáveis não fica evidente quando comparados os valores mais altos de temperatura, em boa medida localizados na porção central (na confluência das regionais leste, nordeste e noroeste e em parte da regional noroeste) e ao norte do município.

Em relação à densidade de volume construído (Figura $3 \boldsymbol{b}$ ), como esperado e diferente do que ocorre com a distribuição da temperatura, nota-se que os valores mais elevados se concentram na região centro-sul de Belo Horizonte, notadamente na área em que se localiza o chamado hipercentro. As menores densidades localizam-se sobretudo a sudeste e a norte, que correspondem a alguns bairros majoritariamente ocupados por unidades de conservação municipais e estaduais (como o Parque Estadual da Serra do Rola Moça e o Parque das Mangabeiras, no limite sudeste), área do aeroporto, do campus universitário da Universidade Federal de Minas Gerais e algumas glebas não parceladas nas regionais Norte e Nordeste. As áreas de menor densidade construída e maiores altitudes na porção sul do município coincidem, por sua vez, com as regiões em que se registrou os menores valores de temperatura do ar.

Em uma análise comparativa inicial, tomando como referência as classes definidas nas figuras $3 b$ e $3 c$, nota-se que não há uma relação direta entre os níveis de densidade de volume construído e a temperatura média (Figura 4). As classes com maior densidade de volume construído (alto e muito alto), mantidas conforme representações utilizadas na Figura $3 \mathrm{~b}$ e $3 \mathrm{c}$ (classificadas pelo método denominado natural breaks), não correspondem àquelas com maior mediana de temperatura. Por outro lado, no que se refere à relação com a variável altitude, os grupos de bairros com densidade de volume construído mais elevados correspondem àqueles com medianas de temperatura mais baixas. Nos níveis muito baixo, baixo e médio de altitude essa relação não se apresenta tão direta. Os escores de regressão linear global (OLS) também não indicam relação direta considerável quando se busca estimar os valores de temperatura média (variável dependente), tendo como base as variáveis densidade de volume construído e altitude. No caso da primeira relação (temperatura e densidade de volume) o valor de $R^{2}\left(R^{2}=0,0059\right)$ é extremamente baixo e não significante. Para a altitude, o coeficiente de determinação $\left(\mathrm{R}^{2}=0,3554\right)$ foi melhor do que o encontrado para a densidade de volume construído, contudo a relação ainda é baixa e inversa. 


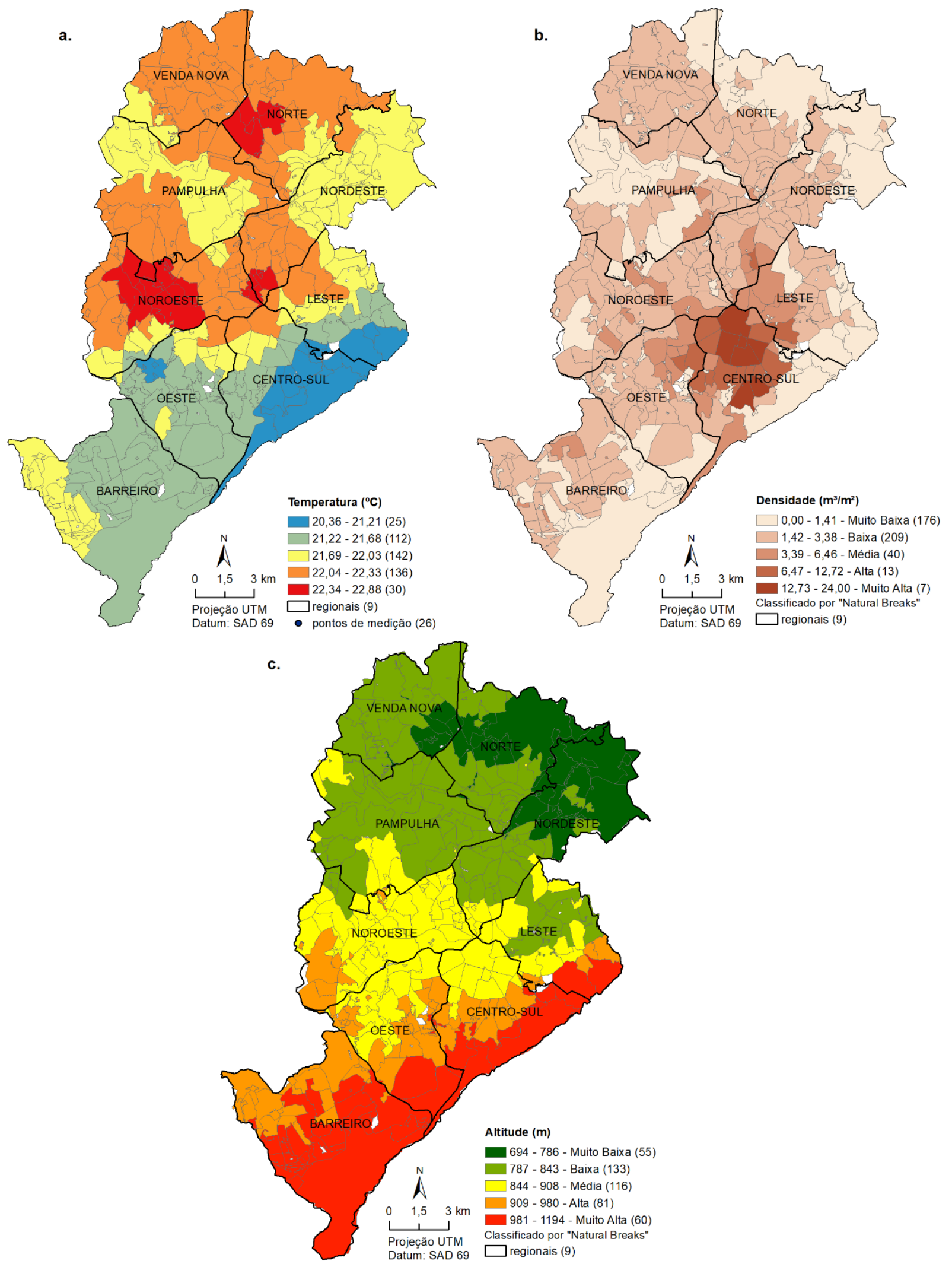

Fonte: Base cartográfica da Prodabel/PBH, Aerolevantamento de 2007/2008 (Prodabel/PBH), Dados de temperatura de Assis (2010), elaboração pelos autores, nov. 2017.

Figura 3: Temperatura média do ar, densidade de volume construído e altitude média por bairros no município de Belo Horizonte/MG. 

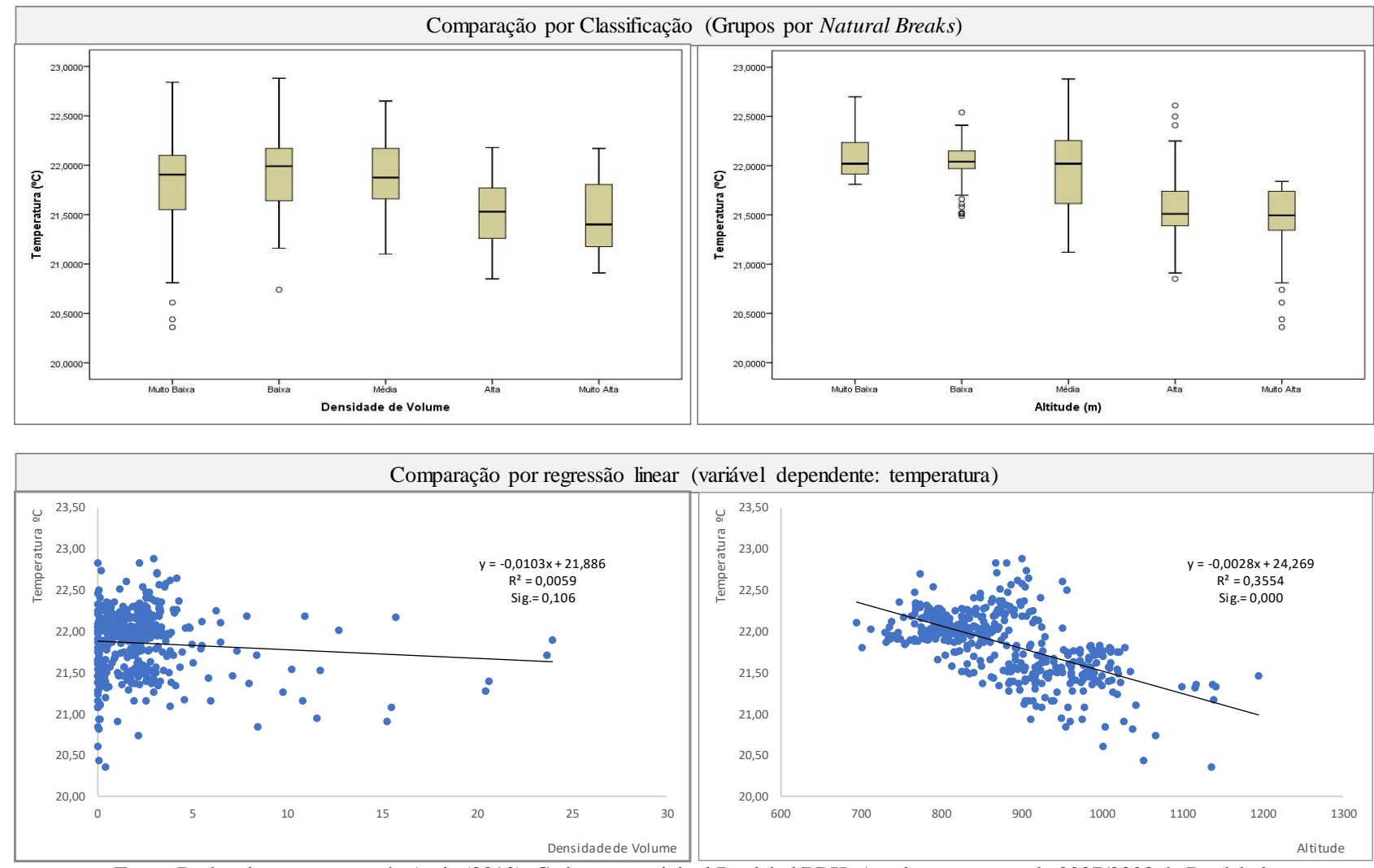

Fonte: Dados de temperatura de Assis (2010), Cadastro municipal Prodabel/PBH, Aerolevantamento de 2007/2008 da Prodabel,

Figura 4: Comparação entre os níveis de temperatura média, conforme altitude média e densidade de volume construído por bairros de Belo Horizonte/MG

A Figura 5 representa os resultados dos escores de $\mathrm{R}^{2}$ local e dos resíduos padronizados do método GWR, considerando as variáveis densidade de volume construído e temperatura média do ar. Em geral, como pode ser observado na Figura 5a, verifica-se uma baixa predição da temperatura tendo como base os valores de densidade de volume construído ( $\mathrm{R}^{2}$ local máximo foi de 0,24$)$. Na maior parte do município o poder explicativo do método espacial foi praticamente nulo. Contudo, é possível observar diferenças regionais significativas do seu nível de ajuste, sendo que os melhores resultados ocorreram majoritariamente em áreas de menor densidade. Quando analisados os resíduos padronizados (Figura $5 \boldsymbol{b}$ ) nota-se que as temperaturas médias foram subestimadas em áreas com baixa densidade volumétrica e superestimadas em alguns bairros de alta densidade na área central da cidade. Dessa forma, áreas com densidade construtiva mais elevada apresentaram médias de temperatura superiores àquelas esperadas pelo modelo, caso a sua predição fosse perfeita.

Valores mais baixos de temperatura média em áreas verticalizadas talvez possam ser justificados pelo sombreamento que ocorre entre os edifícios altos, o que impede a incidência de radiação solar direta (radiação de onda curta) nas faces das edificações durante todo o dia. Áreas com edificações mais baixas e densamente construídas, por sua vez, podem receber radiação solar direta durante praticamente todo o dia, o que eleva a temperatura de suas superfícies e, consequentemente, pode aumentar a temperatura do ar durante o dia (STEWART; OKE, 2012).

Os resultados obtidos da relação entre densidade de volume construído e temperatura parecem convergir com conclusões já apresentadas por Vilela et al. (2009), que observaram baixa correlação entre a variável edificada (massa construída) e a temperatura. Também vai ao encontro com resultados obtidos por Morais (2011) e Gusson e Duarte (2016), que constataram maiores temperaturas em áreas com alta densidade de ocupação, mas com predomínio de edificações baixas. No entanto, contrastam com a relação exposta por $\mathrm{Ng}$ (2015) e outros trabalhos revistos por Ren et al. (2011), que atribuem, de forma empírica, uma relação positiva entre a carga térmica e o volume construído. Estudos em horários específicos (período noturno, por exemplo) eventualmente podem demonstrar este tipo de relação, mas isto não ocorreu no presente trabalho com a análise de dados médios de temperatura. 

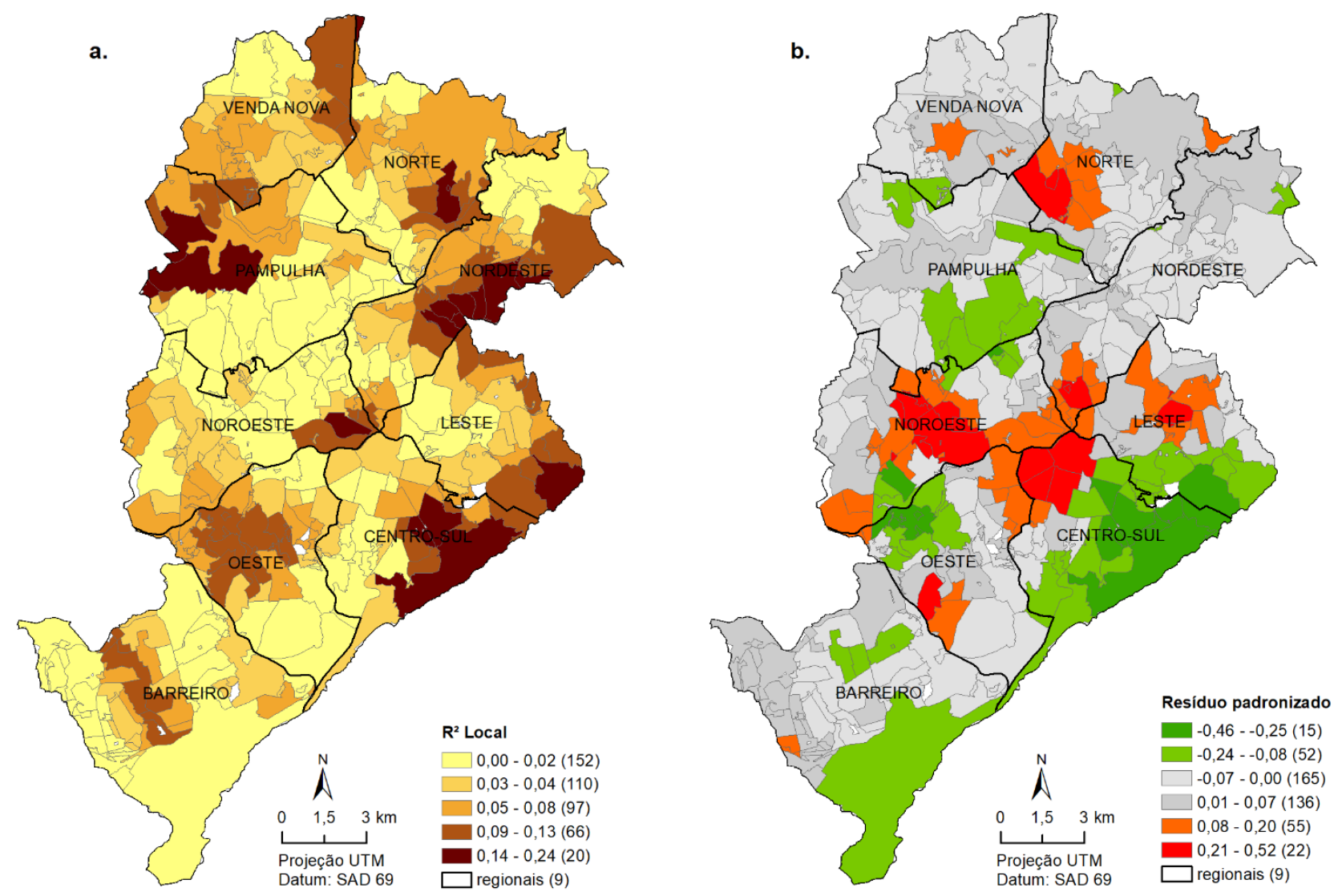

Fonte: Base cartográfica da Prodabel/PBH, Aerolevantamento de 2007/2008 da Prodabel, Dados de temperatura de Assis (2010), elaboração pelos autores, nov. 2017.

Figura 5: Temperatura média (variável dependente) e densidade de volume construído - GWR - Índice de regressão local $\left(\mathrm{R}^{2}\right)$ e Resíduos Padronizados (StdResid) por bairros, Belo Horizonte/MG.

A Figura 6, que estima os escores de regressão no nível local, apresenta os resultados das análises do método GWR para as variáveis altitude e temperatura média do ar. Neste caso, se comparado à densidade de volume construído, o $\mathrm{R}^{2}$ local (Figura 6a) retornou valores maiores. É possível que esses resultados indiquem um predomínio da atuação de componentes naturais na variável temperatura para o caso de Belo Horizonte. Os melhores níveis de ajuste ocorreram na porção leste do município, onde estão concentrados valores altos de altitude média. Os pontos amostrais próximos a Serra do Curral registraram temperaturas mais amenas em relação aos demais locais de coleta. Esses, apesar de urbanizados, possuem algumas características geoecológicas que dificultam a formação de bolsões de calor e áreas de desconforto térmico permanentes. Dentre estas podemos citar a hipsometria, a topografia, a presença de áreas verdes e a inexistência de grandes obstáculos construídos em relação aos ventos predominantes. Desta forma, as características naturais e construídas desta região corroboram para atenuar o efeito da urbanização. Os resíduos padronizados (Figura $\mathbf{6} \boldsymbol{b}$ ) indicam que o método subestima valores de temperatura em bairros com altitude alta na parte leste da cidade e superestima as temperaturas a oeste, em que se observa uma altitude média e, ao mesmo tempo, um valor alto de temperatura.

Apesar da baixa correlação entre as variáveis, observa-se que a melhor relação entre os resultados dos dois modelos ocorreu em áreas de menor densidade construída, maiores altitudes e menores temperaturas, como observado na Figura 3. Uma provável explicação para este resultado é o baixo poder explicativo da relação linear entre a densidade de volume construído e a temperatura do ar e a predominância do efeito do relevo como atenuador da temperatura. Apesar do resultado encontrado ser estatisticamente pouco representativo, verifica-se que a estatística espacial pode auxiliar na análise da interação entre parâmetros climáticos, físicos e urbanos, permitindo extrair relações entre estas variáveis que dificilmente seriam percebidas em análises não espaciais. Ao mesmo tempo, o uso de plataforma SIG permite a atualização constante da informação, sendo que novos dados podem ser agregados aos modelos, melhorando sua capacidade analítica. 

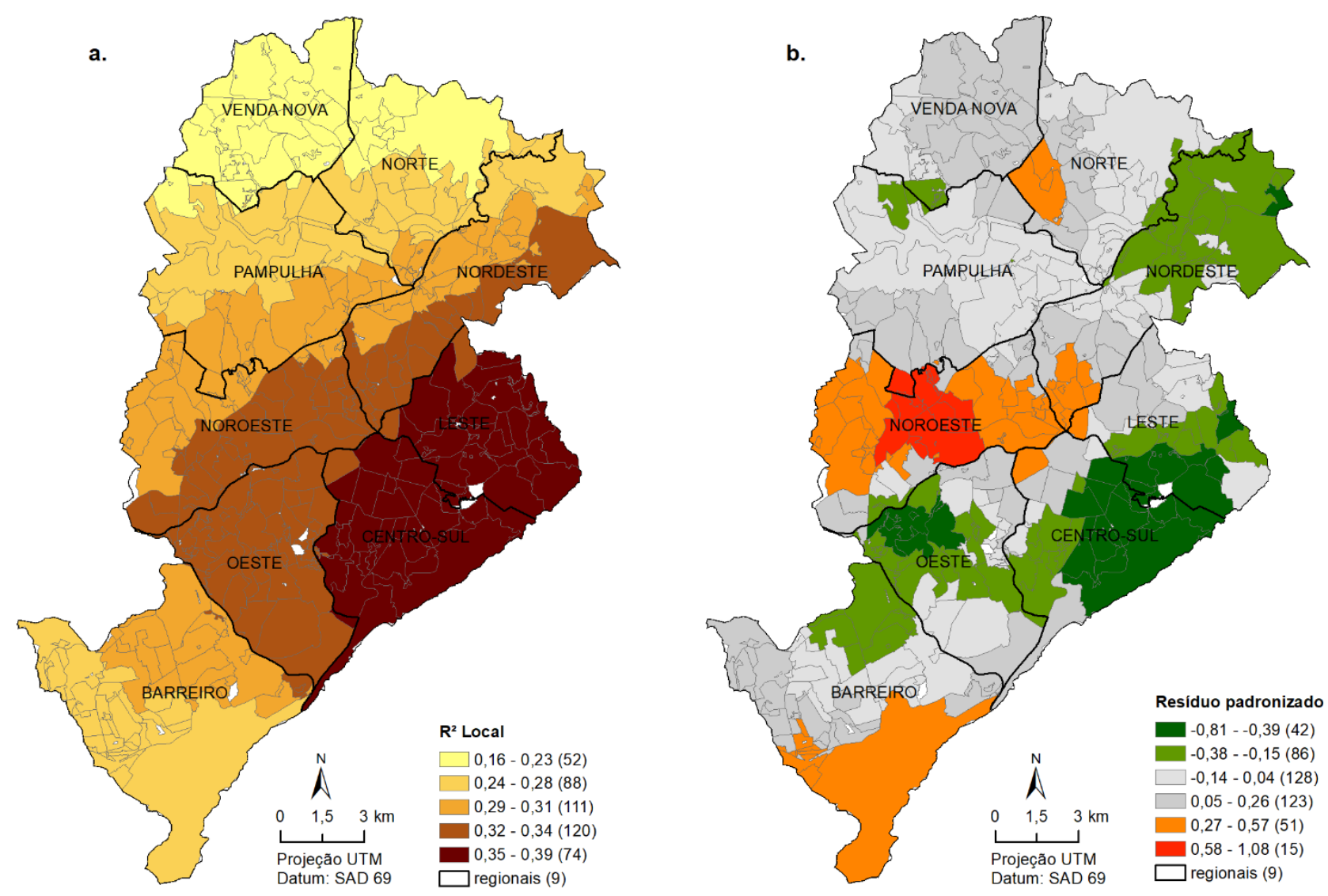

Fonte: Base cartográfica da Prodabel/PBH, Dados de temperatura de Assis (2010), elaboração pelos autores, nov. 2017.

Figura 6: Temperatura média (variável dependente) e altitude - GWR - Índice de regressão local $\left(R^{2}\right)$ e Resíduos Padronizados (StdResid) por bairros, Belo Horizonte/MG.

\section{Considerações Finais}

O balanço de energia no ambiente urbano é alterado por múltiplos fatores, dentre eles, o tipo de uso e ocupação do solo e a topografia, que variam ao longo do território de uma cidade. Uma forma de representar a forma urbana pode ser pelo volume construído, derivado da geometria dos edifícios, por uma unidade de área (densidade de volume construído). Neste artigo pretendeu-se aplicar o método de estatística espacial GWR para verificar a relação deste parâmetro urbano e da topografia com a variação da temperatura do ar na cidade de Belo Horizonte.

Embora os resultados do método GWR não sejam explicativos da variação da temperatura do ar pela densidade de volume construído e pela topografia, os diferentes níveis de ajuste sugerem padrões espaciais distintos. Foi possível observar que nas áreas em que a densidade de volume construído atinge os maiores valores, os métodos de regressão local tendem a estimar temperaturas mais altas do que a observada, o que possivelmente indique uma relação entre a variável climática e a urbana, mas que precisa de avaliação mais aprofundada. A melhor relação linear entre os resultados dos dois modelos, por sua vez, ocorreu em áreas de menor densidade construída, maiores altitudes e menores temperaturas.

Diante dos resultados obtidos, aponta-se a necessidade de incorporar outras variáveis em análises estatísticas, incluindo a coleta de dados em uma amostra mais abrangente na área avaliada, o que poderia indicar outras relações com o clima das cidades, considerando que o sistema clima urbano é complexo e que têm relações intrínsecas entre as variáveis que muitas vezes não podem ser verificadas isoladamente. Mesmo com ressalvas e limitações inerentes ao método, que teoricamente apresenta um tipo de regressão linear, trata-se de uma ferramenta que auxilia na interpretação dos resultados em uma escala local, o que pode melhorar a compreensão da contribuição dos diversos fatores no balanço de energia em ambiente urbano. Assim, a contribuição do trabalho também é no sentido de melhorar as formas de representação das análises em clima urbano, apresentando os resultados em uma linguagem acessível aos planejadores urbanos, em escala de abordagem que é conhecida por estes, apesar de limitada quanto à representatividade dos dados quando distribuídos por territórios administrativos. Além disso, uma abordagem multidisciplinar do ambiente 
urbano, com a avaliação de aspectos físicos e construídos, integrada a técnicas estatísticas, apontam para uma tentativa de visão mais abrangente da temática do clima urbano.

\section{Referências}

ARNFIELD, A. J. Two decades of urban climate research: a review of turbulence, exchanges of energy and water, and the urban heat island. International Journal of Climatology, v. 23, p. 1-26, 2003.

AYOADE, J. O. Introdução a climatologia para os trópicos. Rio de Janeiro: Bertrand Brasil, 1996.

ASSIS, E. S. Aplicações da climatologia urbana no planejamento da cidade: revisão dos estudos brasileiros. RUA. Revista de Arquitetura e Urbanismo, v. 9, p. 20-25, 2006.

ASSIS, W. L. O sistema clima urbano do município de Belo Horizonte na perspectiva têmporoespacial, Belo Horizonte. Tese (Doutorado em Geografia) - Instituto de Geociências, Universidade Federal de Minas Gerais, Belo Horizonte, 2010.

BARRY, R. G.; CHORLEY, R. J. Atmosphere, weather and climate. $9^{a}$ ed. Oxon: Routledge, 2010. xvi, $516 \mathrm{p}$.

GUSSON, C. S.; DUARTE, D. H. S. Effects of Built Density and Urban Morphology on Urban Microclimate - Calibration of the Model ENVI-met V4 for the Subtropical Sao Paulo, Brazil. Procedia Engineering v. 169, p. 2-10, 2016.

IBGE - INSTITUTO BRASILEIRO DE GEOGRAFIA E ESTATÍSTICA. Censo Demográfico 2010: Aglomerados subnormais, Informações territoriais. Rio de Janeiro: IBGE, 2010.

IPEA - INSTITUTO DE PESQUISA ECONÔMICA APLICADA (relator). Relatório brasileiro para o Habitat III. Brasília: ConCidades, IPEA, 2016.

IVANJNSIC, D., KALIGARIC, M., ZIBERNA, I. Geographically weighted regression of the urban heat island of a small city. Applied Geography, v. 53, p. 341-353, 2014.

LANDSBERG, H. E. The urban climate. New York, 1981, 275p.

MONTEIRO, C. A. F. Teoria e clima urbano: um projeto e seus caminhos. In: MENDONÇA, F.; MONTEIRO, C. A. F. (Org.). Clima Urbano. São Paulo: Contexto, 2003.

MORAIS, J. D. M. Análise exploratória de diferenças de conforto térmico entre dois padrões de ocupação urbana representados por ocupação espontânea e por ocupação planejada. 184f. 2011. Dissertação (Mestrado). Escola Politécnica da Universidade Federal da Bahia, Salvador, 2011.

NG, E. Urban climatic map studies in China - Hong Kong. In: NG, E. e REN, C. (Editors). The Urban Climatic Map: A Methodology for Sustainable Urban Planning. 1. ed. New York: Taylor \& Francis Group, 2015.

OKE, T. R. Boundary layer climates. London: New York, 1978, 372p.

OKE, T. R. The energetic basis of the urban heat island. Quarterly Journal of the Royal Meteorological Society, v. 108, p. 1-24, 1982.

OKE, T.; MILLS, G.; CHRISTEN, A.; VOOGT, J. Urban Climates. Cambridge: Cambridge University Press, 2017.

PRODABEL - EMPRESA DE INFORMÁTICA E INFORMAÇÃO DO MUNICÍPIO DE BELO HORIZONTE. Base topográfica digital do município de Belo Horizonte, 2001: Prefeitura Municipal de Belo Horizonte. Escala 1:5.000.

REN, C., NG, E., KATZSCHNER, L. Urban climatic map studies: a review. International Journal of Climatology, v. 31, p. 2213-2233, 2011.

ROGERSON, P. A. Métodos estatísticos para geografia: um guia para o estudante. Porto Alegre: Bookman, 2012.

ROTH, M. Review of urban climate research in (sub)tropical regions. International Journal of Climatology, v. 27, p. 1859-1873, 2007.

STEWART, I. D.; OKE, T. R. Local Climate Zones for urban temperature studies. Bulletin of the American Meteorological Society, v. 93, p. 1879-1900, 2012. 
TSO, C. P.; CHAN, B. K.; HASHIM, M. A. An Improvement to the Basic Energy Balance Model for Urban Thermal Environment Analysis. Energy and Buildings, v. 14, p. 143-152, 1990.

VAREJÃO-SILVA, M. A. Meteorologia e climatologia. Brasília: INMET, Gráfica e Editora Stilo, 2000. 532p.

VILELA, J. A.; ASSIS, E. S.; PAIVA, J. E. M. Variáveis do clima urbano: análise da situação atual e prognósticos para a região do Bairro Belvedere III, Belo Horizonte, MG. In: ENCONTRO NACIONAL E LATINO AMERICANO DE CONFORTO NO AMBIENTE CONSTRUIDO, 9., 2009, Natal. Anais eletrônicos... $\quad 2009$.

<http://www.infohab.org.br/encac/files/2009/ENCAC09_0295_304.pdf>. Acesso em: 03 nov. 2017.

VIANELLO, R. L.; ALVES, A. R. Meteorologia básica e aplicações. Viçosa: UFV, 1991. 449p.

UNITED NATIONS; Department of Economic and Social Affairs; Population Division. World Population Prospects: The 2015 Revision. New York: ESA/P/WP, 2015.

WMO - WORLD METEOROLOGICAL ORGANIZATION. Guide to Meteorological Instruments and Methods of Observation. WMO Report, n. 8, 2012. 